\title{
Planned Subject Number
}

National Cancer Institute

\section{Source}

National Cancer Institute. Planned Subject Number. NCI Thesaurus. Code C49692.

The number of subjects entered in a clinical trial. 